\title{
Characterization of Copper Coating Electrodeposited on Stainless Steel Substrate
}

\author{
Nik Norziehana Che Isa, Yusairie Mohd*, Mohammad Hafizudden Mohd Zaki and \\ Sharifah Aminah Syed Mohamad \\ Faculty of Applied Sciences, Universiti Teknologi MARA, \\ 40450 Shah Alam, Selangor, Malaysia. \\ *E-mail: yusairie@salam.uitm.edu.my
}

doi: $10.20964 / 2017.07 .58$

Received: 30 September 2016 / Accepted: 11 April 2017 / Published: 12 June 2017

The production of copper based products is increased significantly over the years due to a huge industrial interest. This has caused severe depletion of the primary copper ore reserves and the price of solid copper is set to rise. One way of reducing the cost of using solid copper is by producing copper coating which is coated on other cheaper substrates such as stainless steel or aluminum. In this study, copper coating was successfully coated on stainless steel substrate from acidic copper sulfate solution by electrodeposition technique. The characteristic of electrochemical reaction of copper on stainless steel was investigated using cyclic voltammetry. Chronoamperometry was used to further elucidate the nucleation and growth of the copper on stainless substrate. The copper coating was characterized for its surface morphology and crystallography by FESEM and XRD, respectively. A uniform and well adhered copper coating consisting of spherical particles was formed on the stainless steel surface. The particle size, density and surface coverage of copper coating are strongly dependent on deposition conditions (i.e.: applied potential and deposition time) used. XRD patterns confirmed that uniform redbrown color coating deposited on the stainless steel substrate was pure copper with face centered cubic (FCC) crystal lattice. The copper coating can be further investigated for its application for antimicrobial coating.

Keywords: Copper; Copper coating; Cyclic voltammetry; Electrodeposition; Nucleation

\section{$\underline{\text { FULL TEXT }}$}

(C) 2017 The Authors. Published by ESG (www.electrochemsci.org). This article is an open access article distributed under the terms and conditions of the Creative Commons Attribution license (http://creativecommons.org/licenses/by/4.0/). 